\title{
Cost-Effectiveness of Dolutegravir in HIV-1 Treatment- Naive and Treatment-Experienced Patients in Canada
}

\author{
Nicolas Despiégel · Delphine Anger · Monique Martin · Neerav Monga · \\ Qu Cui · Angela Rocchi · Sonia Pulgar · Kim Gilchrist • \\ Rodrigo Refoios Camejo
}

To view enhanced content go to www.infectiousdiseases-open.com

Received: April 10, 2015 / Published online: June 23, 2015

(C) The Author(s) 2015. This article is published with open access at Springerlink.com

\begin{abstract}
Introduction: The Antiretroviral Analysis by Monte Carlo Individual Simulation (ARAMIS) model was adapted to evaluate the costeffectiveness of dolutegravir (DTG) in Canada in treatment-naive (TN) and treatment-
\end{abstract}

Electronic supplementary material The online version of this article (doi:10.1007/s40121-015-0071-0) contains supplementary material, which is available to authorized users.

N. Despiégel · D. Anger ( $\square)$

Mapi, Nanterre, France

e-mail: danger@mapigroup.com

M. Martin

Mapi, Uxbridge, UK

N. Monga - Q. Cui

GlaxoSmithKline, Mississauga, ON, Canada

A. Rocchi

Athena Research, Burlington, ON, Canada

S. Pulgar

Becton, Dickinson and Company, Franklin Lakes,

NJ, USA

K. Gilchrist

GlaxoSmithKline, King of Prussia, PA, USA

R. Refoios Camejo

GlaxoSmithKline, Brentford, UK experienced (TE) human immunodeficiency virus (HIV)-1 patients.

Methods: The ARAMIS-DTG model is a microsimulation model with a lifetime analytic time horizon and a monthly cycle length. Markov health states were defined by HIV health state (with or without opportunistic infection). DTG was compared to efavirenz (EFV), raltegravir (RAL), darunavir/ritonavir, rilpivirine (RPV), elvitegravir/cobicistat, atazanavir/ritonavir and lopinavir/ritonavir in TN patients and to RAL in TE patients. The initial cohort, the main efficacy data and safety data were derived from phase III clinical trials. Treatment algorithms were based on expert opinion. Costs normalized to the year 2013 included antiretroviral treatment cost, testing, adverse event, HIV and cardiovascular disease care and were derived from the literature.

Results: Dolutegravir was estimated to be the dominant strategy compared with all comparators in both $\mathrm{TN}$ and TE patients. Treatment with DTG was associated with additional quality-adjusted life-years that ranged from 0.17 (vs. RAL) to 0.47 (vs. EFV) in TN patients and was 0.60 in TE patients over a lifetime. Cost savings ranged from Can $\$ 1393$ 
(vs. RPV) to Can $\$ 28,572$ (vs. RAL) in $\mathrm{TN}$ patients and amounted to Can\$3745 in TE patients. Sensitivity analyses demonstrated the robustness of the model.

Conclusions: Dolutegravir is a dominant strategy in the management of $\mathrm{TN}$ and $\mathrm{TE}$ patients when compared to recommended comparators. This is mainly related to the high efficacy and high barrier to resistance.

Funding: ViiV Healthcare.

Keywords: Canada; Cost-effectiveness;

Dolutegravir; HIV; Treatment naive

\section{INTRODUCTION}

The human immunodeficiency virus (HIV) is a retrovirus that infects the cells of the immune system and is characterized by a decline in CD4+ cell count and immune function, which can result in life-threatening opportunistic infections (OI), HIV-related cancer and acquired immunodeficiency syndrome (AIDS). HIV represents a global pandemic affecting an estimated 34 million individuals and causing 1.7 million deaths through AIDS or HIV-related illness per year [1]. Currently, there is no cure and, consequently, the aim of antiretroviral (ARV) drugs is to control disease progression through long-term inhibition of HIV replication. During the last 25 years, six new classes of drugs targeting different viral replication mechanisms have emerged, allowing the introduction of new antiretroviral therapies (ARTs) [2]. The use of a combination of three or four ARTs, known as highly active antiretroviral therapy, has resulted in the gradual evolution of HIV from an acute fatal disease into a chronic condition [3]. However, there remains a need for ARTs that can sustain maximal virological suppression and maintain excellent tolerability profiles without compromising on efficacy or protection against the development of resistance.

Dolutegravir (DTG), an integrase inhibitor (INI), was developed to meet this need and was approved in Canada in October 2013. TIVICAY ${ }^{\circledR}$ (ViiV Healthcare, Research Triangle Park, NC, USA), in combination with other antiretroviral agents, is indicated for the treatment of HIV-1 infection in adults and children 12 years of age and older and weighing at least $40 \mathrm{~kg}$. In treatment-naive (TN) patients, DTG demonstrated superiority over efavirenz (EFV) and ritonavir-boosted darunavir (DRV/r) in phase III randomized clinical trials (RCTs) evaluating virological suppression (HIV ribonucleic acid [RNA] $<50$ copies $/ \mathrm{mL})[4,5]$. A network meta-analysis (NMA) [6] supported the finding that DTG resulted in a statistically significant higher probability of virological suppression and higher CD4+ cell increase from baseline at week 48 compared to all nonnucleoside reverse transcriptase inhibitors (NNRTIs) (EFV, rilpivirine [RPV]) and protease inhibitors (PIs) (DRV/r, ritonavir-boosted atazanavir $[\mathrm{ATV} / \mathrm{r}]$, ritonavir-boosted lopinavir $[\mathrm{LPV} / \mathrm{r}]$ ) of interest. A phase III RCT in TN patients demonstrated non-inferiority of DTG relative to raltegravir (RAL) [7]. In treatmentexperienced (TE) patients, a statistically significantly higher proportion of patients with virological suppression was reported in the DTG arm (71\%) compared to the RAL arm (64\%; $P=0.03$ ). The safety profile of DTG is comparable across ARVs, except for EFV having a higher adverse event (AE) discontinuation rate and $\mathrm{DRV} / \mathrm{r}$ having a higher incidence of diarrhea [7-10].

Decision makers evaluate new technologies from clinical and economic perspectives; thus, it is often necessary to demonstrate whether new ARVs represent good value-for-money. This 
is assessed using cost-effectiveness (CE) analyses that compare the relative costs and health effects of two treatment strategies. The result of this evaluation is expressed as a ratio in which the denominator is a gain in health (commonly measured in quality-adjusted lifeyears [QALYs]) and the numerator is the cost associated with the health gain. We present the findings of the CE evaluation of DTG for the treatment of TN and TE HIV-1 patients in the Canadian setting using the Antiretroviral Analysis by Monte Carlo Individual Simulation (ARAMIS)-DTG model. ARAMIS-DTG was developed to simulate the clinical evolution of HIV and assess the CE of DTG compared to the treatment options currently available. The model's structure was derived from the first version of ARAMIS evaluating the $\mathrm{CE}$ of maraviroc (MVC) + optimized background therapy (OBT) versus OBT alone [11], which had been based on the cost-effectiveness of preventing AIDS complications (CEPAC) model [12]. In addition to updating model inputs to reflect the changing nature of HIV, ARAMISDTG included revised treatment algorithms for TN and TE patients, explicitly considered AEs, and explored the link between lipid levels and the risk of cardiovascular disease (CVD) [13].

\section{METHODS}

\section{Model Structure}

ARAMIS-DTG adopted a microsimulation approach, following individual patients transitioning through mutually exclusive health states using a monthly cycle length time. The probability of disease progression was continuously adjusted on individual patient characteristics and the occurrence of events such as virological failure, OI and/or AEs (Fig. 1). Resource use and detriments to health- related quality of life were driven by the levels of CD4+ cell count and accrued over an individual's lifetime. The model was developed for Canada using the perspective of the publicly funded healthcare system.

The population entering the model was defined by age, gender, HIV-1 mRNA level, CD4+ cell count and covariates used in the Framingham equation (systolic blood pressure, diabetes, total cholesterol, and high-density lipoprotein [HDL]) (Supplementary Appendix 2).

Depending on the treatment received, patients faced a probability of experiencing virological suppression (defined as viral load suppression below 50 copies/mL at 48 weeks). Virological suppression led to an increase in the overall CD4+ cell count, which continued to increase as long as patients remained virologically suppressed up to 5 years on successful ART with a maximum possible value of 1200 cells $/ \mu \mathrm{L}$. A steep increase during the first 2 months was assumed, with a slower rate of increase considered afterwards according to clinical trial evidence $[14,15]$. The rate of CD4+ cell recovery was assumed to be treatment specific and based on clinical trial results.

If patients were not virologically suppressed, they would move on to the next treatment regimen following a treatment algorithm derived for each of the comparators on the basis of an advisory board of Canadian HIV clinical experts. Treatment selection was based on the previous treatment and the resistance status (Supplementary Appendix 3).

After moving to the next treatment regimen, patients would then face a probability of experiencing virological suppression under the new regimen. After failing a number of treatments, patients were assumed to have exhausted treatment options, which resulted 


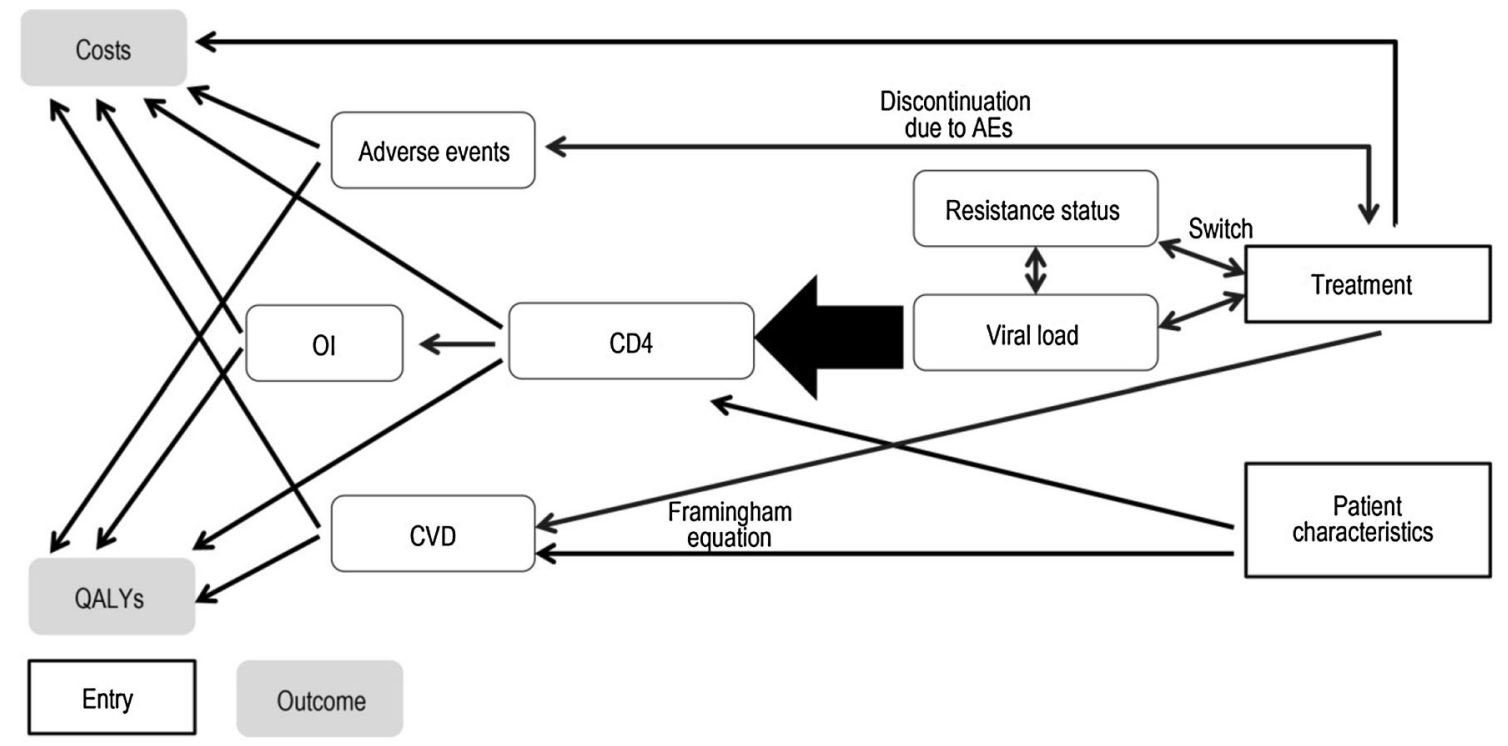

Fig. 1 The interaction between treatment, viral load and CD4+ cell count. $A E$ adverse event, $C V D$ cardiovascular disease, $O I$ opportunistic infection, $Q A L Y$ quality-adjusted life-year

in a decrease in the CD4+ cell count using natural history data and an approach detailed in previously published CE models [16]. In this approach, the CD4+ cell count decline contingent on viral load observed in an untreated population from the Multicenter AIDS Cohort Study [17] was corrected using findings from the Swiss HIV Cohort, which showed that no CD4+ cell count decrease was observed for treated patients with $\log _{10}$ viral loads of four [18].

In addition to the virological suppression rate derived from trials and the consequent CD4+ cell count increase/decrease, the monthly rate of viral rebound after initial viral suppression (commonly known as "late failure rate") was considered from the second year based on long-term evidence from clinical trials [14, 19-25].

The ARAMIS-DTG model allowed up to six successive ARTs for the TN analysis and four successive ARTs for the TE analysis. The number and subsequent efficacy of successive ARTs were contingent upon the resistance status. Resistance to nucleoside reverse transcriptase inhibitors (NRTIs), NNRTIs and INIs was explicitly included in the first two lines of treatment in the TN model and the first line of treatment in the TE model.

The TN model included nine categories of acute AEs in the analysis (diarrhea, nausea, vomiting, rash, nightmares/abnormal dreams, dizziness, depression, insomnia, other AEs). For all AEs, a probability of severity (grade 2-4) and discontinuation due to the $\mathrm{AE}$ were considered using clinical trial evidence. In the TE analysis, as there were no observable differences between the safety profiles of DTG and RAL, only discontinuations due to AEs were considered. Cardiovascular disease was modeled as a monthly risk determined by a Framingham equation (predicting coronary heart disease and stroke). No relationship was assumed between CD4+ cell count and risk of CVD, but the effect of treatment on lipids (total cholesterol and HDL) as observed in clinical trials was considered in the risk equation. 
Mortality was modeled using four main causes of death: HIV, acute OIs, CVD and allcause mortality. HIV mortality was stratified by CD4+ cell count according to natural history data and corrected to account for the benefits of ART [26, 27]. The all-cause mortality rate (excluding HIV- and CVD-related death) was multiplied by a gender-specific standardized mortality ratio from the British Columbia Centre for Excellence (BC-CfE) cohort (Data on file, GlaxoSmithKline. Result tables. Cohort characteristics and mortality in HIV+ patients. HO-13-13512. 2013) [28]. This was applied to account for the fact that HIV patients are expected to have an increased risk of death from other causes related or not to different risk factors [4].

The main model outcomes were (1) total costs, (2) QALYs, (3) incremental costeffectiveness ratios (ICERs) and (4) clinical endpoints (occurrence of OI, cause of death, progression to AIDS, AIDS-free survival, treatment history, time on ART, time on successful therapy, and time on failing therapy).

The model was developed in Microsoft Excel 2007 with Visual Basic for Applications code embedded, and results presented are based on 500,000 simulations. Costs and health outcomes were discounted at a rate of 5\% and no half-cycle correction was applied as the cycle length was small relative to the time horizon (about 30 years in TN patients and 20 years in TE patients).

\section{Model Inputs}

All the data sources used for the model (global and local sources) are summarized in Table 1.

\section{Efficacy Parameters}

The efficacy data applied to the $\mathrm{TN}$ and $\mathrm{TE}$ models are presented in Supplementary
Appendix 4. The DTG phase III clinical trial program was the main source of efficacy data for both analyses. In TN patients, the SINGLE trial (ClinicalTrials.gov \# NCT01263015) evaluated DTG relative to EFV [4], the SPRING-2 trial (ClinicalTrials.gov \# NCT01227824) compared DTG to RAL [7], and the FLAMINGO trial (ClinicalTrials.gov \# NCT01449929) compared DTG to DRV/r [5]. The NMA in TN patients was used to derive efficacy parameters for other comparators when direct head-to-head data were unavailable such as for RPV, elvitegravir/cobicistat (EVG/cobi), ATV/r and $\mathrm{LPV} / \mathrm{r}$ [6]. For the TE INI-naive population comparing DTG to RAL, data were obtained from the SAILING trial (ClinicalTrials.gov \# NCT01231516) [8].

Where data were unavailable after 1 year for comparators, identical efficacy was considered for DTG and the comparator, and identical efficacy parameters were applied to each subsequent regimen, with values obtained from various sources of published clinical evidence and validated by clinical experts. After the trial period, evidence from the STARTMRK trial (ClinicalTrials.gov \# NCT00369941) was used for all treatments to inform the late failure rate and CD4+ cell count increase of patients who maintained virological suppression on their initial treatment [19].

\section{Costs of ART}

The costs of ART were obtained from the Ontario Drug Benefit e-formulary [29]. Dosages used reflected those approved in Canada as indicated in the product monographs. In the TN model, the cost for the backbone as first-line treatment with the third-line agents was based on a blend of Truvada ${ }^{\circledR}$ (tenofovir/emtricitabine [TDF/FTC]; Gilead Sciences, Foster City, CA, USA) and Kivexa ${ }^{\circledR}$ (abacavir [ABC]/lamivudine [3TC]; ViiV Healthcare, Research Triangle Park, 
Table 1 Global and local inputs in the model

\begin{tabular}{|c|c|c|}
\hline Model input & $\begin{array}{l}\text { Global data source } \\
\text { (including clinical trials) }\end{array}$ & Local data source \\
\hline $\begin{array}{l}\text { Efficacy first ART: viral suppression, CD4+ } \\
\text { increase, late failure rate, development of } \\
\text { resistance }\end{array}$ & $\begin{array}{l}\text { SPRING-2, SINGLE, FLAMINGO, } \\
\text { STARTMRK, SAILING, NMA } \\
{[5-9,19]}\end{array}$ & - \\
\hline $\begin{array}{l}\text { Efficacy subsequent ART: viral suppression, } \\
\text { CD4+ increase, late failure rate, } \\
\text { development of resistance }\end{array}$ & $\begin{array}{l}\text { ARTEMIS, TITAN, ODIN, } \\
\text { BENCHMRK, MOTIVATE, } \\
\text { Molina }[14,20-25]\end{array}$ & - \\
\hline Safety data & $\begin{array}{l}\text { SPRING-2, SINGLE, FLAMINGO, } \\
\text { SAILING, NMA [5-9] }\end{array}$ & - \\
\hline $\begin{array}{l}\text { Baseline demographic and disease } \\
\text { characteristics of patient cohort }\end{array}$ & $\begin{array}{l}\text { SPRING-2, SINGLE, FLAMINGO, } \\
\text { SAILING }[5,7-9]\end{array}$ & BC-CfE (SA only) \\
\hline $\begin{array}{l}\text { Clinical comparator and treatment } \\
\text { algorithm }\end{array}$ & - & $\begin{array}{l}\text { Advisory board of Canadian HIV } \\
\text { clinical experts }\end{array}$ \\
\hline Treatment policy (tests, OI prophylaxis) & DHHS guidelines [30] & - \\
\hline $\begin{array}{l}\text { Costs (ART, tests, HIV, AE, OI, CVD, } \\
\text { death) }\end{array}$ & - & $\begin{array}{l}\text { Ontario Drug Benefit e-formulary, } \\
\text { Krentz, Anis, Fassbender, } \\
\text { Smolderen }[29,31-34]\end{array}$ \\
\hline Background mortality & - & Statistics Canada [28] \\
\hline $\begin{array}{l}\text { SMR HIV all-cause mortality vs. general } \\
\text { population }\end{array}$ & - & BC-CfE \\
\hline Incidence and prevalence OI & d'Arminio Monforte [35] & - \\
\hline Lipids & $\begin{array}{l}\text { SPRING-2, SINGLE, FLAMINGO, } \\
\text { NMA [5-9] }\end{array}$ & - \\
\hline Utilities & $\begin{array}{l}\text { Franks [36], SPRING-2, SINGLE, } \\
\text { FLAMINGO, Kauf, Paltiel } \\
\text { (SA only) }[5,7,9,37,38]\end{array}$ & Isogai [39] \\
\hline HIV mortality & MACS, Cole $[17,27]$ & - \\
\hline
\end{tabular}

$A E$ adverse event, $A R T$ antiretroviral therapy, BC-CfE British Columbia Centre for Excellence, $C V D$ cardiovascular disease, DHHS Department of Health and Human Services, HIV human immunodeficiency virus, MACS Multicenter AIDS Cohort Study, NMA network meta-analysis, $O I$ opportunistic infection, $S A$ sensitivity analysis, $S M R$ standardized mortality ratio

NC, USA). The proportion of each of these was based on the clinical trials for DTG (40/60\%, respectively) $[5,7,9]$ and market shares for the comparators (57/43\%, respectively) (Data on file, GlaxoSmithKline. HIV lines of therapy analysis refresh results v2.0. 2013.). For comparators typically used only as fixed-dose combinations (FDC; i.e., EFV, RPV and EVG/cobi), the cost of the FDC was used. In the TE model, the cost of the concomitant 
therapy (i.e., OBT) was based on a combination of $\mathrm{DRV} / \mathrm{r}$ and TDF, the most prevalent regimen in the SAILING trial.

The cost of salvage therapy was based on market shares in fifth-line ART excluding all NRTIs except TDF, EFV and Atripla ${ }^{\circledR}$ (EFV/TDF/ FTC; Bristol-Myers Squibb, New York, NY, USA, and Gilead Sciences) and considering that the regimen would include one ritonavir-boosted PI and two other treatments to be chosen among RAL, ETR, MVC and TDF (IMS Brogan, a unit of IMS Health, Danbury, CT, USA) (Data on file, GlaxoSmithKline. HIV lines of therapy analysis refresh results v2.0. 2013.) on the basis of expert opinion. Estimated cost of salvage was applied to both arms equally. The costs of all ART regimens for each line of treatment of the model are detailed in Table 2.

\section{Healthcare Costs}

The costs of HIV care in Canada were derived from a study by Krentz et al. [31], which reported the cost of medical care for HIV patients from the Southern Alberta Cohort between April 1997 and April 2006. These costs included outpatient care only (HIV clinic visits, HIV-related specialist visits, non-HIV physicians, laboratory tests [CD4+ cell count tests, viral load, HIV genotypic resistance testing, serological tests, hematology, and routine chemistry]). It was assumed that all inpatient stays and emergency room visits were included within the cost of OIs and pre-terminal costs, which were taken from a study by Anis et al. [32, 33]. Neither genotypic resistance testing nor human leukocyte antigen testing was explicitly considered in the model to avoid double counting. All costs considered in the model were inflated to 2013 values considering consumer price index (health and personal care index).

\section{Utilities}

Utilities applied to each CD4+ cell count strata were derived from a study by Isogai et al. [39], which examined the relationship between Health Utility Index-3-derived health preference score and HIV health status measured by CD4+ cell count (Table 2). Disutilities applied to patients developing CVD were derived from Franks et al. [36] and applied using a multiplicative relationship. Disutilities associated with AEs and OIs were not considered in the base case but were explored in sensitivity analyses using published evidence [37, 38] (Table 2).

\section{Sensitivity Analyses}

The uncertainty was investigated through both univariate and structural sensitivity analyses. Univariate analyses focused on parameters expected to impact model results, with ranges defined by estimates of variance (e.g., confidence intervals) or based on clinical expert-validated assumptions. These included the uncertainty surrounding the three efficacy parameters (virological suppression at week 48, late failure between week 48 and week 96 , and CD4+ cell count increase at week 48) (Supplementary Appendix 2); the efficacy of subsequent treatment lines $( \pm 5 \%)$; the costs of subsequent treatment lines $( \pm 10 \%)$; and the cost of salvage treatment $( \pm 25 \%)$. Structural sensitivity analyses were defined to evaluate the robustness of the model when modifying basic model assumptions-modifying the backbone for DTG (100\% Truvada or 100\% Kivexa), the absence of resistance development for DTG and its comparators, using alternative data for utilities, or using alternative discount rates (0\% and $3 \%)$. 
Table 2 Costs and utilities

\begin{tabular}{|c|c|c|}
\hline Costs & Monthly costs (Can\$ 2013) & Source \\
\hline \multicolumn{3}{|l|}{ ART (TN model) } \\
\hline First line & & Ontario Drug Benefit e-formulary [29] \\
\hline $\mathrm{DTG}+2$ NRTIs & 1326.79 & Market shares (IMS Brogan) Advisory board \\
\hline Atripla $^{\circledR}$ & 1296.39 & \\
\hline $\mathrm{RAL}+2$ NRTIs & 1604.89 & \\
\hline $\mathrm{DRV} / \mathrm{r}+2$ NRTIs & 1486.86 & \\
\hline Complera $^{\circledR}$ & 1266.16 & \\
\hline Stribild $^{\circledR}$ & 1383.81 & \\
\hline $\mathrm{ATV} / \mathrm{r}+2 \mathrm{NRTIs}$ & 1519.03 & \\
\hline $\mathrm{LPV} / \mathrm{r}+2 \mathrm{NRTIs}$ & 1450.02 & \\
\hline Second line & $1266.16-1914.13$ & \\
\hline Third line & $1949.77-2208.17$ & \\
\hline Salvage & 2370.95 & \\
\hline \multicolumn{3}{|l|}{ ART (TE model) } \\
\hline First line & & Ontario Drug Benefit e-formulary [29] \\
\hline $\mathrm{DTG}+\mathrm{DRV} / \mathrm{r}+\mathrm{TDF}$ & 1825.43 & Market shares (IMS Brogan) \\
\hline $\mathrm{RAL}+\mathrm{DRV} / \mathrm{r}+\mathrm{TDF}$ & 2083.83 & \\
\hline Second line & 2322.25 & \\
\hline Salvage & 2370.95 & \\
\hline \multicolumn{3}{|c|}{ HIV, CD4+ cell count (cells/ $\mu \mathrm{L})$} \\
\hline$>500$ & 176 & Krentz [31] \\
\hline $350-500$ & 187 & \\
\hline $200-350$ & 210 & \\
\hline $100-200$ & 247 & \\
\hline $50-100$ & 297 & \\
\hline $0-50$ & 397 & \\
\hline \multicolumn{3}{|l|}{ Acute OIs } \\
\hline Bacterial & 1938 & Anis $[32]$ \\
\hline Fungal & 2059 & \\
\hline Protozoal & 2178 & \\
\hline Viral & 2188 & \\
\hline Other OI & 2513 & \\
\hline Death (last 3 months) & 23,667 & Fassbender [33] \\
\hline
\end{tabular}


Table 2 continued

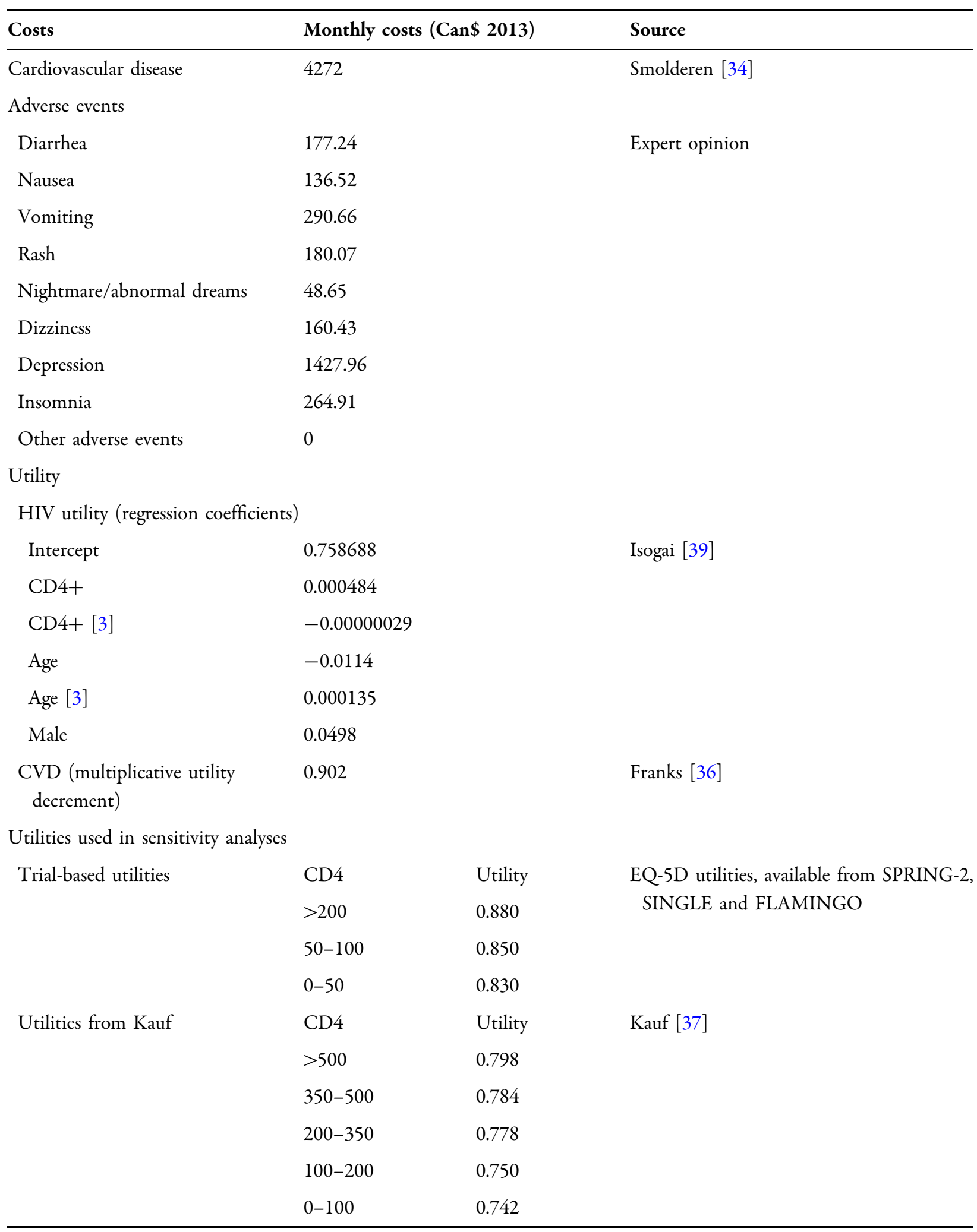


Table 2 continued

\begin{tabular}{llll}
\hline Costs & Monthly costs (Can\$ 2013) & Source \\
\hline Add AE decrements & Any AE grade $\geq 2$ & -0.012 & Simpson [40] \\
& Diarrhea & -0.009 & \\
Nausea & -0.008 & -0.005 \\
Vomiting & -0.01 & \\
Rash/injection site reaction & -0.019 & \\
Nightmares/abnormal dreams & -0.033 & \\
Dizziness & -0.054 & Paltiel [38] \\
Depression & 0 & \\
Insomnia & -0.012 & \\
Other AEs & 0.561 & \\
Bdd OI utilities & Fungal & 0.652 & \\
& Protozoal & 0.561 & 0.652 \\
Viral & 0.561 & \\
\hline
\end{tabular}

$A E$ adverse event, $A R T$ antiretroviral therapy, $A T V / r$ ritonavir-boosted atazanavir, $C V D$ cardiovascular disease, $D R V / r$ ritonavir-boosted darunavir, $D T G$ dolutegravir, $H I V$ human immunodeficiency virus, $L P V / r$ ritonavir-boosted lopinavir, NRTI nucleoside reverse transcriptase inhibitor, $O I$ opportunistic infection, $R A L$ raltegravir, TDF tenofovir, TE treatmentexperienced, $T N$ treatment-naive

\section{Compliance with Ethics Guidelines}

This article does not contain any new studies with human or animal subjects performed by any of the authors.

\section{RESULTS}

\section{HIV-1 TN Patients}

\section{Base Case}

In the TN analysis, DTG was found to be the dominant strategy (i.e., more clinically effective and cost saving) compared with all other treatments considered (Table 3). This result was driven by its superior efficacy in virologic suppression (vs. all comparators except RAL), better resistance profile (vs. EFV, RPV, RAL and EVG/cobi), and/or lower drug acquisition cost (vs. RAL, DRV/r, and ATV/r). Patients were estimated to stay on DTG for approximately 20 months longer than those receiving EFV, 10 months longer versus DRV/r and EVG/cobi and 7 months longer versus RAL. Fewer DTG patients developed AIDS (32\% vs. 37\% in those treated with $\mathrm{EFV}, 34 \%$ vs. DRV/r and RAL, 35\% vs. EVG/cobi). There was an additional 3-8 months of AIDS-free survival in the DTG 
Table 3 Cost-effectiveness results for DTG in TN and TE Patients

\begin{tabular}{|c|c|c|c|c|c|}
\hline Treatment & & DTG & Comparator & Difference & ICER \\
\hline \multicolumn{6}{|l|}{ TN model } \\
\hline \multirow[t]{3}{*}{ EFV $\left(\right.$ Atripla $\left.^{\circledR}\right)$} & Cost (Can\$ 2013) & 315,086 & 322,821 & -7735 & \\
\hline & LY & 27.60 & 27.13 & 0.47 & \\
\hline & QALY & 10.620 & 10.487 & 0.132 & Dominant \\
\hline \multirow[t]{3}{*}{ RAL } & Cost (Can $\$ 2013)$ & 312,943 & 341,516 & $-28,572$ & \\
\hline & LY & 27.56 & 27.39 & 0.17 & \\
\hline & QALY & 10.593 & 10.552 & 0.041 & Dominant \\
\hline \multirow[t]{3}{*}{$\mathrm{DRV} / \mathrm{r}$} & Cost (Can\$ 2013) & 312,128 & 331,221 & $-19,093$ & \\
\hline & LY & 27.59 & 27.38 & 0.22 & \\
\hline & QALY & 10.607 & 10.537 & 0.070 & Dominant \\
\hline \multirow[t]{3}{*}{ RPV $\left(\right.$ Complera $\left.^{\circledR}\right)$} & Cost (Can\$ 2013) & 315,086 & 316,479 & -1393 & \\
\hline & LY & 27.60 & 27.18 & 0.42 & \\
\hline & QALY & 10.620 & 10.506 & 0.114 & Dominant \\
\hline \multirow[t]{3}{*}{ EVG $\left(\right.$ Stribild $\left.^{\circledR}\right)$} & Cost (Can\$ 2013) & 312,943 & 323,918 & $-10,975$ & \\
\hline & LY & 27.56 & 27.28 & 0.28 & \\
\hline & QALY & 10.593 & 10.515 & 0.078 & Dominant \\
\hline \multirow[t]{3}{*}{$\mathrm{ATV} / \mathrm{r}$} & Cost (Can\$ 2013) & 312,128 & 334,860 & $-22,732$ & \\
\hline & LY & 27.59 & 27.29 & 0.30 & \\
\hline & QALY & 10.607 & 10.508 & 0.100 & Dominant \\
\hline \multirow[t]{3}{*}{$\mathrm{LPV} / \mathrm{r}$} & Cost (Can\$ 2013) & 312,128 & 330,877 & $-18,750$ & \\
\hline & LY & 27.59 & 27.22 & 0.38 & \\
\hline & QALY & 10.607 & 10.492 & 0.116 & Dominant \\
\hline \multicolumn{6}{|l|}{ TE model } \\
\hline \multirow[t]{3}{*}{ RAL } & Cost (Can\$ 2013) & 353,957 & 357,702 & -3745 & \\
\hline & LY & 19.57 & 18.97 & 0.60 & \\
\hline & QALY & 8.255 & 8.033 & 0.222 & Dominant \\
\hline
\end{tabular}

$A T V / r$ ritonavir-boosted atazanavir, $D R V / r$ ritonavir-boosted darunavir, $D T G$ dolutegravir, $E F V$ efavirenz, $E V G$ elvitegravir, $I C E R$ incremental cost-effectiveness ratio, $L P V / r$ ritonavir-boosted lopinavir, $L Y$ life-year, $Q A L Y$ qualityadjusted life-year, $R A L$ raltegravir, $R P V$ rilpivirine, $T E$ treatment-experienced, $T N$ treatment-naive

arm. The incremental gain in QALYs over a lifetime ranged from 0.041 (vs. RAL) to 0.132 (vs. EFV). Life expectancy ranged from 27.1 to 27.6 years (given a cohort age of 36.5 years at model entry), and incremental life gains associated with the DTG strategy ranged from 2 months (vs. RAL) to 6 months (vs. EFV). A lower incidence of AIDS was estimated among 
DTG-treated patients, with reductions ranging from $1.5 \%$ (vs. DRV/r) to $4.7 \%$ (vs. EFV). The lifetime cost savings against all comparators ranged from Can\$1393 to Can\$28,572.

\section{Sensitivity Analyses}

These results appear to be fairly robust to variations in any of the model inputs in sensitivity analyses, which contributed to increased confidence in the base case estimates. The only sensitivity analysis under which DTG stopped being dominant was the use of generic EFV + Truvada instead of Atripla. In any case, for this analysis, DTG was still within the range normally considered costeffective with an ICER of Can\$44,604/QALY gained (Supplementary Appendix 5-7).

\section{HIV-1 TE Patients}

\section{Base Case}

For the TE model, DTG was also the dominant strategy over RAL (Table 3). Because of the increased efficacy observed in the SAILING trial, there was a considerably greater lifetime incremental QALY gain for DTG compared to RAL (0.222 QALY). Patients were estimated to stay on DTG for approximately 4 months longer, and live approximately 7 months longer, than those receiving RAL. Fewer DTG patients developed AIDS (73\% compared with $74.6 \%$ of those treated with RAL) and there was an additional 4 months of AIDS-free survival in the DTG arm. DTG-related lifetime savings (amounting to Can\$3745 discounted) were primarily related to the lower drug acquisition cost of DTG versus RAL and the delay in progression to more expensive treatment lines; these were partially offset by additional costs due to the extended survival achieved by DTG patients.

\section{Sensitivity Analyses}

Again, these results in the TE analysis were robust to variations in any of the model inputs in sensitivity analyses, which contributed to increased confidence in the base case estimates. DTG remained dominant in all scenarios, including the use of a discounted price for RAL (Can\$23/day). The sole exception to dominance occurred with the elimination of the discount rate (for costs and effects), but the estimated ICER (Can\$11,787) is well within the range for a drug to be considered cost-effective (Supplementary Appendix 8).

\section{DISCUSSION}

This analysis demonstrates that, in the perspective of the publicly funded healthcare system, DTG is more effective and less costly in the management of both TN and TE patients infected with HIV when compared to the most widely used agents.

Treatment with DTG resulted in incremental QALY gains ranging from 0.041 (vs. RAL) to 0.132 (vs. EFV) over a lifetime in the TN population and a 0.222 incremental QALY gain when compared to RAL in TE patients. The benefits in clinical outcomes were primarily related to the superior efficacy of DTG versus most of the comparators $(>7 \%$ in viral suppression at 48 weeks vs. all comparators, except RAL and EVG/cobi in TN) and/or the prevention of the development of resistance to NRTIs, NNRTIs or INIs (vs. EFV, RAL, RPV and EVG/cobi). However, it should be noted that the conservative assumption on the high efficacy of subsequent treatments meant that patients were kept controlled with high CD4+ cell count levels after their first failure. As a result, the clinical benefit of delaying the switch from the initial treatment only materialized at a late 
stage in a patient's life when it resulted in an increase in life expectancy. This meant that most clinical benefits associated with DTG were accrued later and were consequently affected by the applied discount rate.

The estimated lifetime costs for patients initially treated with DTG were less than those for patients initially treated with any other comparator. In the TN analysis, the use of DTG as the first ART resulted in cost savings to the healthcare system over a lifetime ranging from Can $\$ 1393$ (vs. RPV) to Can $\$ 28,572$ (vs. RAL). The estimated savings were related to lower drug acquisition costs (vs. RAL or ATV/r) or delays in the use of expensive therapy after multiple failures. In the TE population, lower lifetime costs for patients treated with DTG were mainly due to lower drug acquisition costs. These savings in $\mathrm{TN}$ and $\mathrm{TE}$ patients were partially offset by the treatment costs associated with an increase in survival associated with DTG. The additional total costs for treatments that prolong life are an issue previously reported in published CE models in HIV [41]. Obtaining lifetime savings despite these additional costs means that the economic benefits associated with the DTG strategy are very strong. The $\mathrm{CE}$ results presented in this report were shown to be robust in sensitivity analyses. The most influential parameters on the CE of DTG were the acquisition cost for EFV, the choice of the utility source, discount rates, suppression rates at 48 weeks (vs. DRV/r), resistance assumptions (vs. RAL or EFV), and cost of salvage therapy (vs. EFV). However, a change in values for any of these parameters still rendered DTG as the dominant strategy in almost all the sensitivity analyses performed. When DTG stopped being dominant, the resulting ICER was still within the acceptable range for Canada. A conservative approach was adopted by considering the price of the multiple-pill regimen instead of the cheaper fixed-dose combination for DTG.

The approximate life expectancy for patients in the ARAMIS-DTG model was 27-28 years and 20 years for the $\mathrm{TN}$ and $\mathrm{TE}$ populations, respectively. This is slightly higher than that reported in recently published economic evaluations analyzing HIV populations in western countries: CE analyses of RPV and EVG/cobi and analyses based on the CEPAC model reported survival of 11.4-26.5 years in patients initiating ART [42-46]. However, with the increasing efficacy and tolerability of ART, life expectancy reported in the literature may underestimate the current life expectancy of HIV patients initiating ART. For TE patients, the literature estimates vary considerably and range from 8.9 to 29 years. The absolute number of QALYs accrued following ART treatment in ARAMIS-DTG over a lifetime was estimated to be 10.49-10.62, similar to the magnitude of QALYs gained reported in other recently published economic evaluations in western countries (7.2-15.0 QALYs gained) for RAL, RPV, generic EFV and EVG/cobi [44, 47-49].

Two validation exercises were conducted with ARAMIS-DTG to assess the convergent validity of ARAMIS related to the modeling of long-term outcomes of HIV and to assess its real-life predictive power. Firstly, a corroboration exercise between ARAMIS-DTG and CEPAC was conducted using published CEPAC study data [42]. The published CEPAC input parameters were used to populate ARAMIS-DTG, and life expectancy estimates were then compared across models by gender, ethnic groups and late presentations. Furthermore, the impact of structural differences, such as OI and HIV mortality rates, and correction of the HIV mortality for ARV exposure and risk behaviors were assessed between the models one by one and 
simultaneously. When using the same inputs, ARAMIS-DTG provided similar estimates of life expectancy to those from CEPAC (23.20 vs. 22.66 years, respectively). Differences in life expectancy ranged from -1.38 to +2.56 years depending on the subgroups analyzed. The main difference between ARAMIS and CEPAC assumptions appeared to lie in the gender- and ethnic-specific adjustment for risk behaviors, which decreased the life expectancy estimates by 2.61 years relative to the base case. However, all other variations detected between the two models were within $10 \%$ of the absolute life expectancy for the overall population and in nearly all subgroups analyzed.

A second validation exercise compared the incidence of OI and the CD4+ cell count restoration from ARAMIS-DTG with those from an observational cohort of patients initiating ART in the BC-CfE program between 2008 and 2011 (Data on file, GlaxoSmithKline. Result tables. Cohort characteristics and mortality in HIV+ patients. HO-13-13512. 2013). Baseline population characteristics, patient follow-up and treatment efficacy were modified to reflect the observational cohort in the model, and mean changes in CD4+ cell count and incidence rates of AIDS-related events were simulated in ARAMIS-DTG. In particular, the suppression rate at 48 weeks and late failure rates were adjusted to replicate the time on treatment observed in the BC-CfE cohort. The impact of relevant ARAMIS parameters on these outcomes, such as mortality or virological suppression, was assessed in sensitivity analyses. In the base case analysis, the average CD4+ cell count over five years increased from 295 to 682 cells $/ \mu \mathrm{L}$ in ARAMIS-DTG and from 303 to 532 cells/ $\mu \mathrm{L}$ in the BC-CfE cohort, reflecting a potential overestimation of adherence in the clinical trial setting. However, despite a higher CD4+ cell count, the incidence of AIDS-related events was also higher in ARAMIS: 3.81 vs. 2.84 per 100,000 person-years, which suggests that the higher incidence of AIDS-related events in ARAMISDTG was mostly attributable to the pre-2005 rates used to inform the model; including a CD4+ restoration rate and OI incidence that reflect recent real-life evidence might further increase the validity of the ARAMIS-DTG model.

However, the model still possesses some limitations. Laboratory testing was not explicitly measured as it could not be separated out from overall HIV care costs per CD4+ cell count presented in Krentz et al. As DTG was associated with a longer time on treatment and a delayed time to switching therapy, not considering test costs separately arguably resulted in underestimation of the savings due to fewer resistance tests in the DTG arm. Productivity costs were not included because of the lack of recent data in Canada, but including these would have reinforced the savings associated with DTG. The higher efficacy observed for DTG is translated to a lower proportion of patients with a CD4+ cell count lower than 200 cells $/ \mu \mathrm{L}$ and, consequently, in a lower risk of OIs, which are directly associated with productivity losses [50, 51].

A complex treatment algorithm was designed to account for the consequences of class resistance on the number of available strategies and their efficacy. This part required simplifications that are necessary in all CE models as it cannot represent the diversity of the parameters considered when selecting another regimen after virologic failure. Furthermore, the number of remaining strategies is a structural assumption in the model, and their efficacy was derived from selected clinical trials. However, the sensitivity analysis removing the impact of resistance on the choice of the next treatment did not alter the conclusions of the CE analysis. 


\section{CONCLUSION}

DTG fulfills a clinical need among patients infected with HIV across the whole spectrum of the disease by offering high-level efficacy combined with advantages in tolerability and a high barrier to resistance. This economic evaluation demonstrated that DTG is more effective and less costly (i.e., economically dominant) in the management of TN and TE HIV patients when compared to recommended treatments in the Canadian setting.

\section{ACKNOWLEDGMENTS}

Funding for this work and article processing charges were provided by ViiV Healthcare. All named authors meet the International Committee of Medical Journal Editors (ICMJE) criteria for authorship for this manuscript, take responsibility for the integrity of the work as a whole, and have given final approval to the version to be published. The authors wish to acknowledge the following individual for editorial assistance during the development of this manuscript: Chris Lawrence.

Conflict of interest. Nicolas Despiégel was an employee of OptumInsight at the time of the study and received study funding from ViiV Healthcare. Delphine Anger, Monique Martin, and Angela Rocchi have declared no conflicts of interest. Neerav Monga, Qu Cui, and Sonia Pulgar were employees of GSK at the time of the study. Kim Gilchrist owns stock in BMS, AZ, and GSK. Rodrigo Refoios Camejo is an employee of and owns stock in GSK.

Compliance with ethics guidelines. This article does not contain any new studies with human or animal subjects performed by any of the authors.

Open Access. This article is distributed under the terms of the Creative Commons Attribution Noncommercial License which permits any noncommercial use, distribution, and reproduction in any medium, provided the original author(s) and the source are credited.

\section{REFERENCES}

1. World Health Organization. Fast facts on HIV. http://www.who.int/hiv/data/fast_facts/en/. Accessed Nov 10, 2014.

2. Canadian Agency for Drugs and Technologies in Health. https://www.cadth.ca/fr. Accessed May 28, 2015.

3. Palella FJ Jr, Delaney KM, Moorman AC, et al. Declining morbidity and mortality among patients with advanced human immunodeficiency virus infection. HIV Outpatient Study Investigators. N Engl J Med. 1998;338:853-60.

4. Walmsley S, Antela A, Clumeck $\mathrm{N}$, et al. Dolutegravir (DTG; S/GSK1349572) + abacavir/ lamivudine once daily statistically superior to tenofovir/emtricitabine/efavirenz: 48-week results-SINGLE (ING114467). In: Presented at: 52nd Interscience Conference on Antimicrobial Agents and Chemotherapy: San Francisco; Sept 9-12, 2012.

5. Clotet B, Feinberg J, van Lunzen J, et al. Once-daily dolutegravir versus darunavir plus ritonavir in antiretroviral-naive adults with HIV-1 infection (FLAMINGO): 48 week results from the randomised open-label phase $3 \mathrm{~b}$ study. Lancet. 2014;383:2222-31.

6. Patel DA, Snedecor SJ, Tang WY, et al. 48-week efficacy of dolutegravir relative to commonly used 3rd agents in treatment-naive HIV-1-infected patients: a systematic review and network metaanalysis. In: Presented at: 14th European AIDS Conference: Brussels; Oct 16-19 2013.

7. Raffi F, Jaeger H, Quiros-Roldan E, et al. Once-daily dolutegravir versus twice-daily raltegravir in antiretroviral-naive adults with HIV-1 infection (SPRING-2 study): 96 week results from a 
randomised, double-blind, non-inferiority trial. Lancet Infect Dis. 2013;13:927-35.

8. Cahn P, Pozniak AL, Mingrone $\mathrm{H}$, et al. Dolutegravir versus raltegravir in antiretroviralexperienced, integrase-inhibitor-naive adults with HIV: week 48 results from the randomised, doubleblind, non-inferiority SAILING study. Lancet. 2013;382:700-8.

9. Walmsley SL, Antela A, Clumeck N, et al. Dolutegravir plus abacavir-lamivudine for the treatment of HIV-1 infection. $\mathrm{N}$ Engl J Med. 2013;369:1807-18.

10. Molina JM, Clotet B, van Lunzen J, et al. Once-daily dolutegravir is superior to once-daily darunavir/ ritonavir in treatment-naïve HIV-1-positive individuals: 96 week results from FLAMINGO. J Int AIDS Soc. 2014;17(4 suppl 3):19490.

11. Kühne FC, Chancellor J, Mollon $\mathrm{P}$, et al. A microsimulation of the cost-effectiveness of maraviroc for antiretroviral treatment-experienced HIV-infected individuals. HIV Clin Trials. 2010;11:80-99.

12. Rydzak CE, Cotich KL, Sax PE, et al. Assessing the performance of a computer-based policy model of HIV and AIDS. PLoS One. 2010;5:e12647.

13. Cooper A, Nherera L, Calvert N, et al. Clinical guidelines and evidence review for lipid modification: cardiovascular risk assessment and the primary and secondary prevention of cardiovascular disease. Appendix H: Framingham equation. London: National Collaborating Centre for Primary Care and Royal College of General Practitioners; 2008.

14. Gulick RM, Lalezari J, Goodrich J, et al. Maraviroc for previously treated patients with R5 HIV-1 infection. N Engl J Med. 2008;359:1429-41.

15. Nelson M, Arastéh K, Clotet B, et al. Durable efficacy of enfuvirtide over 48 weeks in heavily treatment-experienced HIV-1-infected patients in the T-20 versus optimized background regimen only 1 and 2 clinical trials. J Acquir Immune Defic Syndr. 2005;40:404-12.

16. Mauskopf J, Brogan AJ, Talbird SE, et al. Costeffectiveness of combination therapy with etravirine in treatment-experienced adults with HIV-1 infection. AIDS. 2012;26:355-64.

17. Mellors JW, Muñoz A, Giorgi JV, et al. Plasma viral load and CD4+ lymphocytes as prognostic markers of HIV-1 infection. Ann Intern Med. 1997;126:946-54.

18. Ledergerber B, Lundgren JD, Walker AS, et al. Predictors of trend in CD4-positive T-cell count and mortality among HIV-1-infected individuals with virological failure to all three antiretroviraldrug classes. Lancet. 2004;364:51-62.

19. Rockstroh JK, DeJesus E, Saag M, et al. Long-term safety and efficacy of raltegravir (RAL)-based versus efavirenz (EFV)-based combination therapy in treatment-naïve HIV-1 infected patients: final 5-year double-blind results from STARTMRK. In: Presented at: XIX International AIDS Conference: Washington, DC; July 22-27, 2012.

20. Cahn P, Fourie J, Grinsztejn B, et al. Week 48 analysis of once-daily vs. twice-daily darunavir/ ritonavir in treatment-experienced HIV-1-infected patients. AIDS. 2011;25:929-39.

21. De Meyer S, Lathouwers E, Dierynck I, et al. Characterization of virologic failure patients on darunavir/ritonavir in treatment-experienced patients. AIDS. 2009;23:1829-40.

22. Madruga JV, Berger D, McMurchie M, et al. Efficacy and safety of darunavir-ritonavir compared with that of lopinavir-ritonavir at 48 weeks in treatment-experienced, HIV-infected patients in TITAN: a randomised controlled phase III trial. Lancet. 2007;370:49-58.

23. Molina JM, Lamarca A, Andrade-Villanueva J, et al. Efficacy and safety of once daily elvitegravir versus twice daily raltegravir in treatment-experienced patients with HIV-1 receiving a ritonavir-boosted protease inhibitor: randomised, double-blind, phase 3, non-inferiority study. Lancet Infect Dis. 2012;12:27-35.

24. Ortiz R, DeJesus E, Khanlou H, et al. Efficacy and safety of once-daily darunavir/ritonavir versus lopinavir/ritonavir in treatment-naive HIV-1infected patients at week 48. AIDS. 2008;22:1389-97.

25. Steigbigel RT, Cooper DA, Kumar PN, et al. Raltegravir with optimized background therapy for resistant HIV-1 infection. N Engl J Med. 2008;359:339-54.

26. Multicenter AIDS Cohort Study (MACS) public dataset: release PO4. Springfield: National Technical Information Service; 1995.

27. Cole SR, Hernán MA, Robins JM, et al. Effect of highly active antiretroviral therapy on time to acquired immunodeficiency syndrome or death using marginal structural models. Am J Epidemiol. 2003;158:687-94.

28. Statistics Canada. Mortality, summary list of causes. 2009. http://www.statcan.gc.ca/pub/ 84f0209x/84f0209x2009000-eng.pdf. Accessed Nov 10, 2014. 
29. Ontario Drug Benefit Formulary/Comparative Drug Index. https://www.healthinfo.moh.gov.on.ca/ formulary/index.jsp. Accessed Jan 18, 2013.

30. Panel on Antiretroviral Guidelines for Adults and Adolescents. Guidelines for the use of antiretroviral agents in HIV-1-infected adults and adolescents. http://aidsinfo.nih.gov/contentfiles/lvguidelines/ adultandadolescentgl.pdf. Accessed Dec 2, 2013.

31. Krentz HB, Gill MJ. Cost of medical care for HIVinfected patients within a regional population from 1997 to 2006. HIV Med. 2008;9:721-30.

32. Anis AH, Guh D, Hogg RS, et al. The cost effectiveness of antiretroviral regimens for the treatment of HIV/AIDS. Pharmacoeconomics. 2000;18:393-404.

33. Fassbender K, Fainsinger RL, Carson M, et al. Cost trajectories at the end of life: the Canadian experience. J Pain Symptom Manage. 2009;38:75-80.

34. Smolderen KG, Bell A, Lei Y, et al. One-year costs associated with cardiovascular disease in Canada: insights from the REduction of Atherothrombosis for Continued Health (REACH) registry. Can J Cardiol. 2010;26:297-305.

35. d'Arminio Monforte A, Sabin CA, Phillips A, et al. The changing incidence of AIDS events in patients receiving highly active antiretroviral therapy. Arch Intern Med. 2005;165:416-23.

36. Franks P, Hanmer J, Fryback DG. Relative disutilities of 47 risk factors and conditions assessed with seven preference-based health status measures in a national U.S. sample: toward consistency in costeffectiveness analyses. Med Care. 2006;44:478-85.

37. Kauf TL, Roskell N, Shearer A, et al. A predictive model of health state utilities for HIV patients in the modern era of highly active antiretroviral therapy. Value Health. 2008;11:1144-53.

38. Paltiel AD, Scharfstein JA, Seage GR III, et al. A Monte Carlo simulation of advanced HIV disease: application to prevention of CMV infection. Med Decis Mak. 1998;18(suppl 2):S93-105.

39. Isogai PK, Rueda S, Rachlis AR, et al. Prediction of health preference values from $\mathrm{CD} 4$ counts in individuals with HIV. Med Decis Mak. 2013;33:558-66.

40. Simpson KN, Chen SY, Wu AW, et al. Costs of adverse events among patients with human immunodeficiency virus treated with nonnucleoside reverse transcriptase inhibitors. In: Presented at: ISPOR 17th Annual International Meeting: Washington, DC; Jun 2-6, 2012.
41. Mauskopf J, Brogan A, Martin S, et al. Cost effectiveness of darunavir/ritonavir in highly treatment-experienced, HIV-1-infected adults in the USA. Pharmacoeconomics. 2010;28(suppl 1):83-105.

42. Losina E, Touré H, Uhler LM, et al. Costeffectiveness of preventing loss to follow-up in HIV treatment programs: a Côte d'Ivoire appraisal. PLoS Med. 2009;6:e1000173.

43. Brogan AJ, Talbird SE, Cohen C. Cost-effectiveness of nucleoside reverse transcriptase inhibitor pairs in efavirenz-based regimens for treatment-naive adults with HIV infection in the United States. Value Health. 2011;14:657-64.

44. Juday $\mathrm{T}$, Correll $\mathrm{T}$, Bentley $\mathrm{T}$, et al. Costeffectiveness of elvitegravir/cobicistat/ emtricitabine/tenofovir compared with efavirenz/ emtricitabine/tenofovir as first-line HIV antiretroviral therapy in the adult population in the United States. In: Presented at: ISPOR 18th Annual International Meeting: New Orleans; May 18-22, 2013.

45. Sloan CE, Champenois K, Choisy P, et al. Newer drugs and earlier treatment: impact on lifetime cost of care for HIV-infected adults. AIDS. 2012;26:45-56.

46. Tilden D, Jackson D, LeReun C, et al. A modelled economic evaluation of raltegravir compared to standard practice in Australia for treatment naive patients with HIV. In: Presented at: ISPOR 4th AsiaPacific Conference: Phuket; Sept 5-7, 2010.

47. Chaudhary MA, Elbasha EH, Kumar RN, et al. Costeffectiveness of raltegravir in HIV/AIDS. Expert Rev Pharmacoecon Outcomes Res. 2011;11:627-39.

48. Girod I, Bell M, Adriaenssen I, et al. Costeffectiveness of rilpivirine- or efavirenz-based regimens for treatment-naive, HIV-1-infected patients: NHS England perspective. In: Presented at: 18th Annual Conference of the British HIV Association: Birmingham; Apr 18-20, 2012.

49. Walensky RP, Sax PE, Nakamura YM, et al. Economic savings versus health losses: the costeffectiveness of generic antiretroviral therapy in the United States. Ann Intern Med. 2013;158:84-92.

50. Liu GG, Yin DD, Lyu R, et al. Economic costs of HIV infection: an employer's perspective. Eur J Health Econ. 2002;3:226-34.

51. Sendi P, Schellenberg F, Ungsedhapand C, et al. Productivity costs and determinants of productivity in HIV-infected patients. Clin Ther. 2004;26:791-800. 